\title{
Association between carotid-femoral pulse wave velocity and overall cardiovascular risk score assessed by the SCORE system in urban Polish population
}

\author{
Mateusz Podolec ${ }^{1,2,3 *}$, Aleksander Siniarski ${ }^{2,3 *}$, Andrzej Pająk $k^{4}$, Paweł Rostoff', 3 , Grzegorz Gajos ${ }^{2,3}$, \\ Jadwiga Nessler ${ }^{2,3}$, Maria Olszowska ${ }^{3,5}$, Michał Nowakowski ${ }^{1}$, Krystyna Szafraniec ${ }^{4}$, Grzegorz Kopeć ${ }^{3,5}$ \\ 'Department of Medical Education, Faculty of Medicine, Jagiellonian University Medical College, Krakow, Poland \\ ${ }^{2}$ Department of Coronary Artery Disease and Heart Failure, Faculty of Medicine, Jagiellonian University Medical College, Krakow, Poland \\ ${ }^{3}$ John Paul II Hospital, Krakow, Poland \\ ${ }^{4}$ Department of Epidemiology and Population Studies, Institute of Public Health, Faculty of Health Sciences, Jagiellonian University \\ Medical College, Krakow, Poland \\ ${ }^{5}$ Department of Cardiac and Vascular Disease, Faculty of Medicine, Jagiellonian University Medical College, Krakow, Poland \\ *Both authors contributed equally to the study.
}

\begin{abstract}
A bstract
Background: The Systemic COronary Risk Estimation (SCORE) system is recommended for the assessment of cardiovascular disease (CVD) death risk in individuals free of CVD.

Aim: We sought to determine the association between carotid-femoral pulse wave velocity (CFPWV) and SCORE.

Methods: The study involved 1008 Krakow residents, and a random subsample of 3424 men and 3205 women who participated in Wave 2 of the Polish part of the Health, Alcohol, and Psychosocial factors in Eastern Europe (HAPIEE) study. At baseline we performed a medical interview, physical examination, evaluation of present comorbidities, medications using standardised

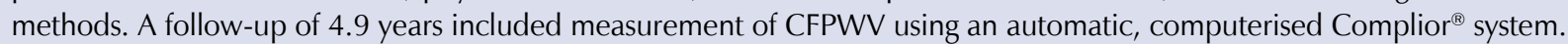

Results: Final analysis included 720 patients (378 women), aged $58.5 \pm 6.5$ years at baseline. In 488 individuals without history of CVD and/or diabetes, SCORE was calculated. Median CFPWV was higher $(p=0.002)$ in men $(12.5 \mathrm{~m} / \mathrm{s}$; interquartile range [IQR] 10.3-15.7) than in women (11.7 m/s; IQR 10.1-13.7). High CFPWV (> $10 \mathrm{~m} / \mathrm{s})$ was observed in 270 men (78.9\%) and in 285 women (75.4\%). We observed a strong association between high CVD risk (SCORE $\geq 5 \%$ ) and high CFPWV (odds ratio $2.29 ; 95 \%$ confidence interval 1.17-4.46). The CFPWV cut-off value to differentiate between patients with low and high CVD risk was $11.7 \mathrm{~m} / \mathrm{s}$ (with $58.6 \%$ sensitivity and $71.3 \%$ specificity, $\mathrm{AUC}=0.68$ ).

Conclusions: Our study is the first to describe the distribution of CFPWV in the adult Polish population. SCORE $\geq 5 \%$ predicted high CFPWV in 4.9 years of follow-up, which was independent of other risk factors. CFPWV $>11.7 \mathrm{~m} / \mathrm{s}$ was most valid in relation to high CVD risk.
\end{abstract}

Key words: cardiovascular, carotid-femoral, pulse wave velocity, risk, SCORE, tables

Kardiol Pol 2019; 77, 3: 363-370

\section{INTRODUCTION}

Arterial stiffness is a biomechanical property of the arterial wall expressed as a change of pressure-volume relationship [1-3]. Carotid-femoral pulse wave velocity (CFPWV) is the most common method widely used for aortic stiffness measurement [3]. It has been shown that increased CFPWV correlates with an increased risk of cardiovascular death in patients with hypertension [4, 5] and type 2 diabetes (T2D) [6, 7].

Mateusz Podolec, MD, PhD, Department of Coronary Artery Disease and Heart Failure, Faculty of Medicine, Jagiellonian University Medical College, ul. Prądnicka 80, 31-202 Kraków, Poland, tel: +48 1261422 18, fax: +48 1243343 76, e-mail: podolecmateusz@gmail.com Received: 6.11.2018 Accepted: 7.02.2019 Available as AoP: 7.02.2019 
Furthermore, CFPWV was an independent predictor of coronary artery disease (CAD) [8] and was recognised as a new risk factor of morbidity and mortality in cardiovascular (CV) disease (CVD) [9]. CFPWV is a useful non-invasive method for measuring the stiffness of the aorta because of its simplicity, repeatability, and accuracy. According to the recent European Society of Cardiology (ESC)/European Society of Hypertension (ESH) guidelines for hypertension, pulse wave velocity (PWV) may be considered in the assessment of arterial stiffness as an integral part of the overall assessment of subjects with hypertension [10].

The association between CFPWV and a single risk factor such as hypertension is well-known; however, SCORE and CFPWV analysis, although not well documented, indirectly estimates how the PWV affects the 10-year risk of death due to CVDs.

Moreover, CFPWV was proven to predict CVD in a variety of populations independently of traditional CV risk factors $[4,11]$. Therefore, the $2013 \mathrm{ESH} / \mathrm{ESC}$ guidelines for the management of hypertension recommend measuring CFPWV as a marker of target organ damage in order to improve CV risk prediction [12-14]. The objective of this study was to evaluate the association between CVD risk factors and CVD risk assessed by Systematic COronary Risk Evaluation (SCORE) and CFPWV measured four years later. Additionally, our goal was to describe the distribution of CFPWV in adult urban Polish population and to estimate the cut-off point for CFPWV which is related to SCORE $\geq 5 \%$.

\section{METHODS Patients}

The study involved 1008 Krakow residents (478 men and 530 women), aged $58.5 \pm 6.5$ years, and a random (chosen based on a random number generator programme) subsample of 3424 men and 3205 women who participated in Wave 1 and Wave 2 (4.9 years apart) of the Polish part of the Health, Alcohol, and Psychosocial factors in Eastern Europe (HAPIEE) study. In Wave 1, to assess risk factors, the study participants were visited at home to complete a structured questionnaire and were then invited to a clinic for a thorough medical interview to evaluate comorbidities and medications, and for a physical examination. Detailed information on the HAPIEE study, which involved a representative sample of permanent residents of Krakow, was published earlier [15].

For the present analysis, current smoking was defined as smoking at least one cigarette daily. Prior to the blood pressure (BP) measurement, participants were asked to sit quietly for 5-10 min. BP was measured three times, with a 2-min interval between measurements, which was done using an Omron M5-I device (Omron Healthcare, Kyoto, Japan). Arterial hypertension was defined as a systolic $\mathrm{BP} \geq 140 \mathrm{mmHg}$, or diastolic BP $\geq 90 \mathrm{mmHg}$, or taking antihypertensive drugs within the last 14 days prior to the examination. History of
CAD was established based on a medical interview including documented history of myocardial infarction (MI) or prior cardiac procedures of CAD. T2D diagnosis was based on medical history of T2D treatment or American Diabetes Association criteria. Obesity was diagnosed when body mass index $(\mathrm{BMI}) \geq 30 \mathrm{~kg} / \mathrm{m}^{2}$ or waist circumference $\geq 94 \mathrm{~cm}$ in men or $80 \mathrm{~cm}$ in women. Family history of CAD, stroke, or T2D was considered positive when at least one of the first-degree relatives had a history of at least one of the diseases.

The Jagiellonian University Ethical Committee approved the study, and all the participants provided their written, informed consent (No. KE/99/03/B/284, amendment from March 13, 2008).

\section{Sample collection and routine laboratory tests} Fasting blood samples $(25 \mathrm{~mL})$ were obtained from an antecubital vein and were immediately drawn into the tubes containing 3.2\% trisodium citrate. Samples were processed 30 to 60 min after blood collection. Serum total cholesterol (TC), low-density lipoprotein cholesterol (LDL-C), high-density lipoprotein cholesterol (HDL-C), triglyceride (TG), and glucose were determined using a Cobas $6000^{\mathrm{TM}}$ biochemical analyser (Roche Diagnostics GmbH, Mannheim, Germany). Dyslipidaemias including hypercholesterolaemia and hypertriglyceridaemia were diagnosed in accordance with the European Guidelines on CVD prevention and dyslipidaemias [16].

\section{Measurement of CFPWV}

Carotid-femoral pulse wave velocity was measured in Wave 2 of the HAPIEE study. To assess CFPWV we used the non-invasive, automatic, computerised Complior ${ }^{\circledR}$ system in accordance with the system protocol. All measurements were performed after a $10 \mathrm{~min}$ rest in a supine position $\left(\sim 30^{\circ}\right)$. Mechanical transducers sensitive to deformation of the vessel wall were applied over the common carotid artery and right femoral artery. Then, the distance between the suprasternal notch and the top of the femoral transducer were calculated on the surface of the body with a measuring tape. The CFPWV was calculated by dividing distance (d) of the wave from the carotid to femoral artery over time (t) as shown below [17]: $\mathrm{CFPWV}=\mathrm{d} / \mathrm{t}$.

Carotid-femoral pulse wave velocity values $>10 \mathrm{~m} / \mathrm{s}$ were defined as "high" according to the current guidelines of the ESC and the ESH $[10,18,19]$.

\section{SCORE assessment}

The SCORE system is a calculation of the 10-year risk of a fatal CVD in European countries by sex, age, systolic BP, TC, and smoking status $[16,20]$. For eligible participant (without a history of CAD and/or T2D), CVD risk was assessed using the SCORE system calibrated for Poland available on the ESC website (www.heartscore.org; access from January 2007 to December 2009) [21]. 


\section{Statistical analysis}

The Shapiro-Wilk test was used to assess the normality of distribution. Distribution of the continuous variables was described by mean and standard deviation (SD) or median and interquartile range (IQR). The Student $t$ test or Mann-Whitney $\mathrm{U}$ test was applied to test the between-sex differences. For categorical variables, an absolute number and percentage was presented and the between-sex differences were tested using the $\chi^{2}$ test. Spearman rank correlation coefficients were calculated to test the association between the continuous variables. Stepwise logistic regression analysis was performed to determine the independent predictors of increased CFPWV in the study groups. Despite differences in distribution of characteristics between men and women, the direction and pattern of the association between these variables and CFPWV were homogeneous. Therefore, data were pooled for multivariate analysis including sex as an independent variable. The association between the variables was presented as odds ratio (OR) with corresponding 95\% confidence interval $(\mathrm{Cl})$. The calibration and discrimination of the developed logistic regression model were assessed using the Hosmer-Lemeshow statistic and the area under the receiver operating characteristic curve (AUC), respectively. Two-sided p-values $<0.05$ were considered statistically significant. All calculations were done using STATISTICA version 10 PL software package (StatSoft, Inc., Tulsa, Oklahoma, USA).

\section{RESULTS}

Final analysis included 720 participants (378 women and 342 men). At baseline (Wave 1), mean age was 58.1 and 58.8 years, respectively. At Wave 2, participants were older by an average of 4.9 years (4.9 in men and 4.8 in women; Table 1). A total of 179 (24.9\%) participants had previously diagnosed CAD and 97 had history of T2D, and SCORE was not calculated for these individuals because by definition they were considered high-risk subjects. Therefore, final analysis for SCORE included 229 men and 259 women.

The CFPWV ranged from 2.3 to $37.5 \mathrm{~m} / \mathrm{s}$ in men and from 2.4 to $31.8 \mathrm{~m} / \mathrm{s}$ in women. The distribution of CFPWV was skewed in both sexes, and the median was higher in men $(12.5 \mathrm{~m} / \mathrm{s}$; IQR $10.3-15.7)$ than in women $(11.7 \mathrm{~m} / \mathrm{s}$; IQR 10.1-13.7); $p=0.002$ (Fig. 1). For the entire sample CFPWV ranged from 2.3 to $37.5 \mathrm{~m} / \mathrm{s}$ and the median CFPWV was $12.0 \mathrm{~m} / \mathrm{s}$ (IQR 10.2-14.7). High CFPWV (> $10 \mathrm{~m} / \mathrm{s}$ ), which is considered abnormal [14, 19], was observed in $270(78.9 \%)$ men and in $285(75.4 \%)$ women. In the entire sample $555(77.1 \%)$ individuals had high CFPWV.

The distribution of SCORE was skewed particularly in women (Fig. 2). Median SCORE was higher in men (9.0\%; IQR 5.0-14.0) than in women (3.0\%; IQR 1.0-6.0); $p<0.001$. High risk (SCORE $\geq 5 \%$ ) was found in $28.6 \%$ of women and in $77.7 \%$ of men $(p<0.001)$.

Descriptive statistics for the remaining traits that were analysed are presented according to sex in Table 1. Smok- ing and T2D were more prevalent in men, and $\mathrm{BP}$ was not significantly higher in men than in women. TC and HDL-C were higher in women, and TGs were higher in men. There was no between-sex difference in LDL-C, and there was no difference in the combined prevalence of dyslipidaemias. The prevalence of obesity was similar in men and women, but the median waist circumference was lower in women, which reflects the between-sex differences in body constitution.

After adjustment for baseline age, the risk of high CFPWV ( $>10 \mathrm{~m} / \mathrm{s}$ ) increased with the increase of systolic BP in both sexes and with diastolic BP and the presence of hypertension in women. In women the risk of high CFPWV increased with the increase of BMl and waist circumference. We found a positive association between CFPWV and both blood glucose and TC, but only in male population. In women with no history of CVD or T2D $(n=488)$, there was a positive relation between the high CFPWV and SCORE (OR 1.42; 95\% Cl 1.11-1.81 per $1 \%$ increase). The relation between the high CFPWV and SCORE was not significant in men (Table 2). Triglycerides and smoking as well as other characteristics listed in Table 1 were not associated with high CFPWV.

In individuals without CVD or T2D, after adjustment for age, sex, BMI, blood TG, and glucose, we did not found a continuous relation between SCORE and CFPWV. It was attenuated and remained not significant mainly after inclusion of the age into the model. However, there was a strong relation between high CVD risk (SCORE $\geq 5 \%$ ) and high CFPWV (OR 2.29; 95\% Cl 1.17-4.46). Further analysis after subdivision of the group with high CVD risk (SCORE > 5\%) changed the average estimates (OR 2.29; 95\% Cl 1.15-4.55 for SCORE 5\%-9\%; and OR 2.27; 95\% Cl 0.92-5.62 for SCORE $\geq 10 \%$ ).

The calculated CFPWV cut-off value to differentiate between participants with low and high CVD risk (SCORE of $<5 \%$ vs. SCORE $\geq 5 \%$ ) was $11.7 \mathrm{~m} / \mathrm{s}$ (with $58.6 \%$ sensitivity and $71.3 \%$ specificity, $\mathrm{AUC}=0.68$ ).

\section{DISCUSSION}

Knowledge about the association between CFPWV and the result of commonly used CVD risk assessment systems such as the SCORE system is still limited [22-24]. Because most European countries use different SCORE charts, it is particularly important to assess its results with other measurements. This could improve the quality of CVD predictions in this particular population, including subpopulations, that is, men and women. Therefore, to our knowledge, we are first to demonstrate the association of CFPWV and the SCORE system in any Polish population.

We demonstrated that high CVD risk assessed by the SCORE system predicted high CFPWV at almost five years of follow-up. A continuous relation between SCORE and high CFPWV was attenuated after adjustment for covariates, particularly for age, which suggests a confounding effect that was not strong enough to wave the relation for the range 
Table 1. Demographic and clinical data of the study participants $(n=720)$

\begin{tabular}{|c|c|c|c|}
\hline Variable & Women $(n=378)$ & Men $(n=342)$ & p \\
\hline Baseline age (Wave 1) [years] & $58.1 \pm 6.5$ & $58.8 \pm 6.4$ & 0.156 \\
\hline Age at Wave 2 [years] & $63.0 \pm 6.5$ & $63.7 \pm 6.5$ & 0.144 \\
\hline Average follow-up time [years] & $4.8 \pm 0.3$ & $4.9 \pm 0.3$ & 0.291 \\
\hline BMI $\left[\mathrm{kg} / \mathrm{m}^{2}\right]$ & $27.1(23.8-29.8)$ & $27.1(25.0-29.7)$ & 0.437 \\
\hline Waist circumference $[\mathrm{cm}]$ & $91.0(82.0-98.0)$ & $99.0(93.0-106.0)$ & $<0.001$ \\
\hline Obesity & $91(24.1)$ & $74(21.6)$ & 0.437 \\
\hline CAD & $103(27.2)$ & $76(22.2)$ & 0.12 \\
\hline Type 2 diabetes: & $37(9.8)$ & $60(17.5)$ & 0.002 \\
\hline Treated with diet only & $9(2.4)$ & $20(5.9)$ & 0.030 \\
\hline Treated with diet and insulin & $2(0.5)$ & $5(1.5)$ & \\
\hline Treated with diet and oral medications & $21(5.6)$ & $28(8.2)$ & \\
\hline Untreated & $5(1.3)$ & $7(2.1)$ & \\
\hline Hypertension: & $207(54.8)$ & $199(58.2)$ & 0.355 \\
\hline Treated with antihypertensives & $152(40.2)$ & $140(40.9)$ & 0.513 \\
\hline Never treated & $55(14.6)$ & $59(17.3)$ & \\
\hline Dyslipidaemia & $202(53.4)$ & $163(47.7)$ & 0.121 \\
\hline Consistent daily smokers & $69(18.3)$ & $94(27.5)$ & $<0.001$ \\
\hline Occasional smokers & $10(2.7)$ & $8(2.3)$ & \\
\hline Former smokers & $72(19.1)$ & $113(33.0)$ & \\
\hline Never smokers & $227(60.1)$ & $127(37.1)$ & \\
\hline Family history of CAD & $135(35.7)$ & $107(31.3)$ & 0.209 \\
\hline Family history of stroke & $29(7.7)$ & $15(4.4)$ & 0.066 \\
\hline Family history of type 2 diabetes & $50(13.2)$ & $38(11.1)$ & 0.387 \\
\hline SCORE scale [\%] $(n=488)$ & $3.0(1.0-6.0)$ & $9.0(5.0-14.0)$ & $<0.001$ \\
\hline$\leq 4 \%$ & $185(71.4)$ & $51(22.3)$ & $<0.001$ \\
\hline $5-9 \%$ & $57(22.0)$ & $85(37.1)$ & \\
\hline$\geq 10 \%$ & $17(6.6)$ & $93(40.6)$ & \\
\hline Systolic BP [mmHg] & $129.8(117.0-145.5)$ & $139.0(128.0-151.0)$ & $<0.001$ \\
\hline Diastolic BP [mmHg] & $82.5(76.0-91.0)$ & $88.0(80.5-94.0)$ & $<0.001$ \\
\hline Mean arterial pressure $[\mathrm{mmHg}]$ & $98.4(99.9-108.4)$ & $104.7(97.2-112.8)$ & $<0.001$ \\
\hline Glucose $[\mathrm{mmol} / \mathrm{L}]$ & $5.0(4.6-5.5)$ & $5.2(4.8-5.8)$ & $<0.001$ \\
\hline Heart rate $[\mathrm{bpm}]$ & $74.0(67.5-82.5)$ & $73.5(66.0-82.0)$ & 0.451 \\
\hline $\mathrm{TC}[\mathrm{mmol} / \mathrm{L}]$ & $5.80(5.12-6.54)$ & $5.59(4.99-6.28)$ & 0.008 \\
\hline $\mathrm{HDL}-\mathrm{C}[\mathrm{mmol} / \mathrm{L}]$ & $1.52(1.26-1.82)$ & $1.29(1.08-1.48)$ & $<0.001$ \\
\hline LDL-C [mmol/L] & $3.57(2.98-4.20)$ & $3.53(2.99-4.10)$ & 0.810 \\
\hline TG [mmol/L] & $1.30(1.01-1.84)$ & $1.49(1.13-2.07)$ & $<0.001$ \\
\hline CFPWV [m/s] (measured at 4.9 years of follow-up) & $11.7(10.1-13.7)$ & $12.5(10.3-15.7)$ & 0.002 \\
\hline
\end{tabular}

Data presented as number (percentage), mean \pm standard deviation or median (interquartile range). BMI — body mass index; BP — blood pressure; CAD - coronary artery disease; CFPWV — carotid-femoral pulse wave velocity; HDL-C — high-density lipoprotein cholesterol; LDL-C — low-density lipoprotein cholesterol; SCORE — Systemic COronary Risk Estimation; TC — total cholesterol; TG — triglycerides

of SCORE over $5 \%$. The calculated CFPWV cut-off point of $11.7 \mathrm{~m} / \mathrm{s}$ allowed us to classify participants of the study to the high CVD risk group with optimal sensitivity and specificity.

The SCORE system is a well-recognised tool used to evaluate 10-year CVD risk. On the other hand, the SCORE system was calibrated for specific countries, which allowed adjustment for CVD mortality and exposure to risk factors. Poland is a country with high exposure to CVD risk factors [25-28]. The most frequent CVD risk factors in Poland are hypercholesterolaemia, hypertension, and cigarette smoking [29]. Our results 


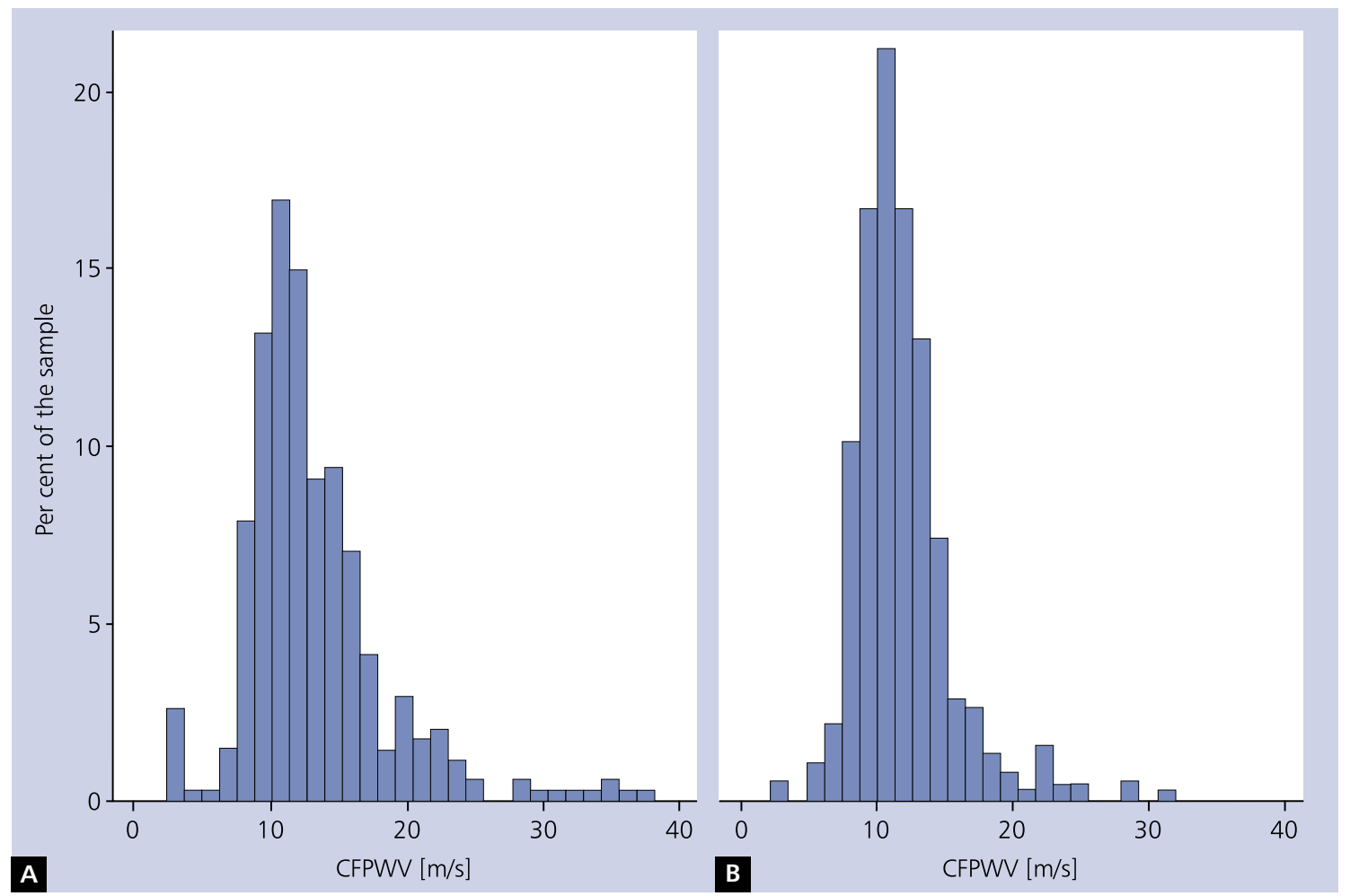

Figure 1. Distribution of carotid-femoral pulse wave velocity (CFPWV) by sex in the study population. A. Men; B. Women. Data shown as percentage and meters per second

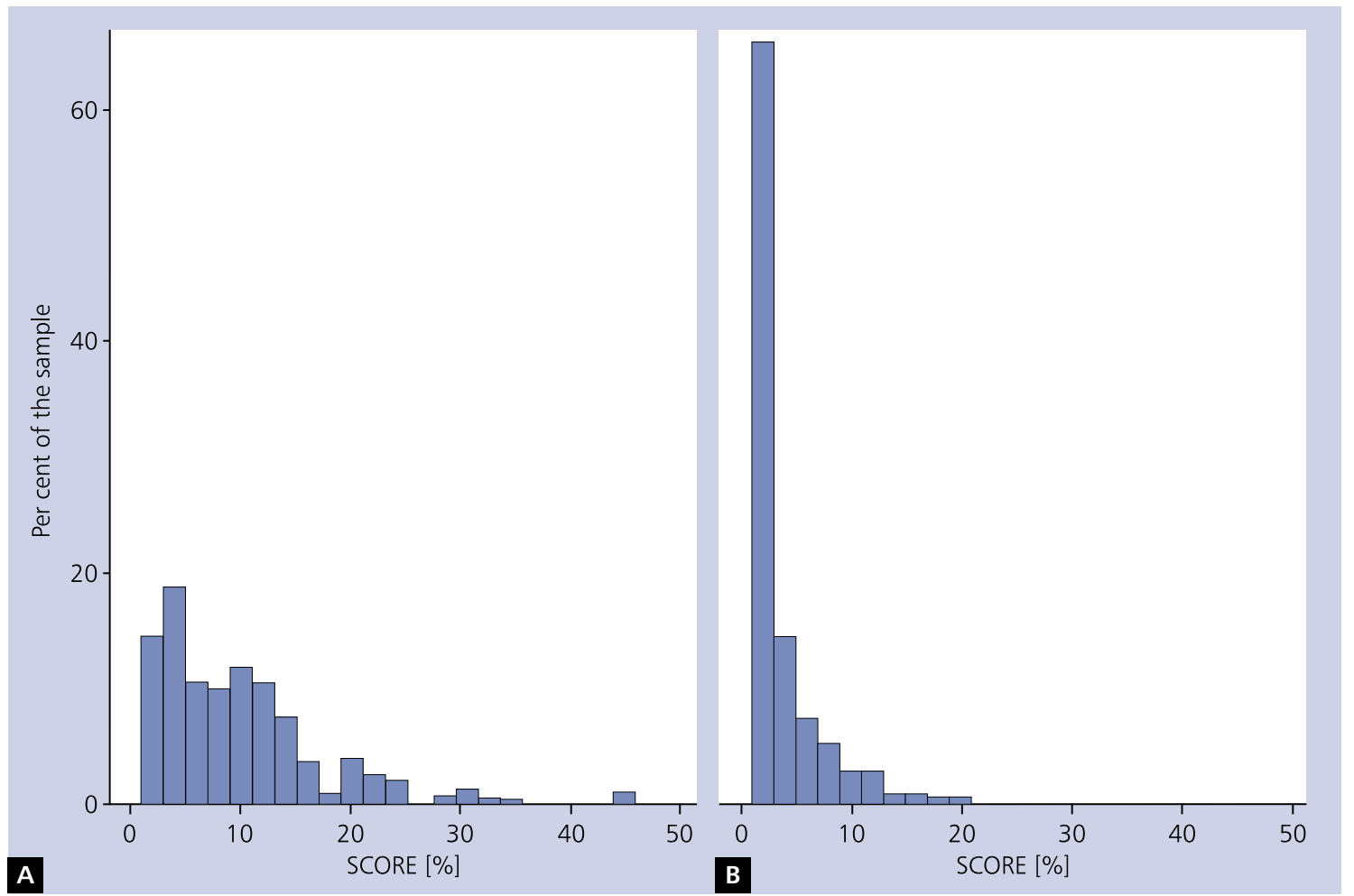

Figure 2. Distribution of Systemic COronary Risk Evaluation (SCORE) by sex in the study population; A. Men; B. Women. Data shown as percentage of the study population and percentage of SCORE system 
Table 2. Age-adjusted relations between the high carotid-femoral pulse wave velocity (>10 m/s) and blood pressure, obesity, blood lipids, smoking, and Systemic COronary Risk Estimation

\begin{tabular}{lcc} 
Variable & \multicolumn{1}{c}{ Age adjusted OR (95\% CI) } \\
\cline { 2 - 3 } & Women & Men \\
\hline Diastolic BP, per $1 \mathrm{mmHg}$ increase & $1.04(1.01-1.06)$ & $1.02(0.99-1.05)$ \\
Systolic BP, per $1 \mathrm{mmHg}$ increase & $1.03(1.01-1.04)$ & $1.02(1.001-1.05)$ \\
MAP, per $1 \mathrm{mmHg}$ increase & $1.04(1.01-1.06)$ & $1.63(0.95-2.83)$ \\
Hypertension*, yes vs. no & $2.56(1.52-4.29)$ & $1.07(0.99-1.15)$ \\
BMI, per $1 \mathrm{~kg} / \mathrm{m}^{2}$ increase & $1.11(1.04-1.18)$ & $1.02(0.99-1.04)$ \\
Waist circumference, per $1 \mathrm{~cm}$ increase & $1.03(1.01-1.05)$ & $1.34(1.01-1.79)$ \\
Glucose, per $1 \mathrm{mmol} / \mathrm{L}$ increase & $1.34(0.95-1.88)$ & $1.33(1.002-1.76)$ \\
TC, per $1 \mathrm{mmol} / \mathrm{L}$ increase & $1.13(0.89-1.44)$ & $0.94(0.68-1.29)$ \\
TG, per $1 \mathrm{mmol} / \mathrm{L}$ increase & $1.46(0.98-2.72)$ & $0.80(0.46-1.41)$ \\
Smoking (current vs. non- and ex-smokers) & $0.84(0.47-1.49)$ & $1.01(0.95-1.07)$ \\
SCORE, per $1 \%$ increase & $1.42(1.11-1.81)$ & \\
\hline
\end{tabular}

*Systolic BP $\geq 140 \mathrm{mmHg}$ or diastolic BP $\geq 90 \mathrm{mmHg}$ and/or at BP lowering treatment; $\mathrm{Cl}$ — confidence interval; MAP — mean arterial pressure; OR — odds ratio; other abbreviations — see Table 1

are in accordance with another study which demonstrated that arterial stiffness (assessed by CFPWV among other parameters) was also positively associated with SCORE, but in that study the authors did not attempt to assess a cut-off point for CFPWV, which allowed to classify the participants into the high and low CVD risk groups [22].

In the 2013 ESC guidelines for the management of arterial hypertension, a measurement of CFPWV was recommended in all individuals with arterial hypertension [14, 19]. However, in the $2018 \mathrm{ESH} / \mathrm{ESC}$ guidelines there was no such recommendation. Nevertheless, PWV is considered as one of the key factors influencing CV risk in patients with asymptomatic hypertension-mediated organ damage [10]. Moreover, CFPWV over $10 \mathrm{~m} / \mathrm{s}$ was for many years considered a risk factor for CVD [14, 19]. Greve et al. [30] analysed the data from over 2500 patients and demonstrated an increase in the CFPWV associated with atherosclerotic plaques and increased rate of albuminuria to creatinine ratio depending on the high and very high risk assessed by the SCORE system and Framingham risk scale. The authors emphasised that PWV better predicted CVD complications in high-risk subjects [30]. It was reported that PWV is associated with the severity of CAD: $11.13 \pm 0.91 \mathrm{~m} / \mathrm{s}$, $15.22 \pm 1.11 \mathrm{~m} / \mathrm{s}$, and $19.30 \pm 2.05 \mathrm{~m} / \mathrm{s}$ for one-, two-, and three-vessel CAD, respectively [31]. Similarly, Kopeć et al. [32] observed that increased aortic wall stiffness (aortic PWV) was associated with the severity of CAD. Invasive measurements of aortic PWV were linked with worse endothelial function in patients with angiographically confirmed CAD, independent of sex [32]. Higher CFPWV was also observed in individuals with microvascular angina compared to a healthy control group (9.3 m/s vs. $8.2 \mathrm{~m} / \mathrm{s}$, respectively) [33]. Recent studies show that the assessment of PWV as an indicator of arterial stiffness is still a widely used parameter [34, 35].
We have several limitations to acknowledge. The most important is that we were not able to adjust for the baseline CFPWV, which did not allow us to address the problem of overtime change and limited our ability to address the problem of causality. Also, there was no information on changes in the exposure to risk factors after the baseline examination, so their directions and magnitudes could not be evaluated. Second, age as a CVD risk factor interferes with arterial stiffness and, by definition, is associated with the results of the SCORE system. Third, our study population was not representative of the entire Polish population and involved a local population of residents of one city (second largest city in Poland). Further, earlier observations of the HAPIEE cohort showed that study participants were healthier compared to non-participants. Still, nearly $6 \%$ of the total sample examined at baseline did not survive to participate in PWV measurement at five years of follow-up [36]. The latter could lead to elimination of the high-risk group, and it is possible that it could attenuate slightly the relation between SCORE and CFPWV. Fourth, as mentioned above, the SCORE system appeared to overestimate CVD risk in the Polish HAPIEE sample [37]. Also, classification into the groups of high and very high CVD risk could be biased as compared to real risk. Finally, the expert consensus for measurement of aortic stiffness recommends use of $80 \%$ of the direct carotid-femoral distance as the most accurate distance estimate [18]; however, we performed our measurements using the protocol of the device used in the study (Complior ${ }^{\circledR}$ system).

Our study is the first to describe the distribution of CFPWV in the adult urban Polish population. SCORE $\geq 5 \%$ predicted high CFPWV in 4.9 years of follow-up, which was independent of other risk factors, and CFPWV > 11.7 appeared to be most valid in relation to high CVD risk. 


\section{Acknowledgements}

This work was supported by a grant from Jagiellonian University Medical College (grant No. K/ZDS/007181, to P.R.).

The HAPIEE study was supported by the Welcome Trust (grants No. 064947/Z/01/Z and No. 081081/Z/06/Z), US National Institute on Ageing (grant No. 1 R01 AG23522-01), and MacArthur Foundation Initiative on Social Upheaval and Health (award 71208).

\section{Conflict of interest: none declared}

\section{References}

1. Quinn U, Tomlinson LA, Cockcroft JR. Arterial stiffness. JRSM Cardiovasc Dis. 2012; 1(6), doi: 10.1258/cvd.2012.012024, indexed in Pubmed: 24175072.

2. Safar ME, Frohlich ED (eds). Arterial stiffness: A simplified overview in vascular medicine. Atherosclerosis, large arteries and cardiovascular risk. Adv. Cardiol. Basel, Karger Publishers 2007; Vol. 44, pp: 1-18.

3. Laurent S, Cockcroft J, Van Bortel L, et al. European Network for Non-invasive Investigation of Large Arteries. Expert consensus document on arterial stiffness: methodological issues and clinical applications. Eur Heart J. 2006; 27(21): 2588-2605, doi: 10.1093/eurheartj/ehl254, indexed in Pubmed: 17000623.

4. Laurent S, Boutouyrie P, Asmar R, et al. Aortic stiffness is an independent predictor of all-cause and cardiovascular mortality in hypertensive patients. Hypertension. 2001; 37(5): 1236-1241, indexed in Pubmed: 11358934.

5. Boutouyrie P, Tropeano AI, Asmar R, et al. Aortic stiffness is an independent predictor of primary coronary events in hypertensive patients: a longitudinal study. Hypertension. 2002; 39(1): 10-15, indexed in Pubmed: 11799071.

6. Shoji T, Emoto M, Shinohara K, et al. Diabetes mellitus, aortic stiffness, and cardiovascular mortality in end-stage renal disease. J Am Soc Nephrol. 2001; 12(10): 2117-2124, indexed in Pubmed: 11562410.

7. Cruickshank K, Riste L, Anderson SG, et al. Aortic pulse-wave velocity and its relationship to mortality in diabetes and glucose intolerance: an integrated index of vascular function? Circulation. 2002; 106(16): 2085-2090, indexed in Pubmed: 12379578.

8. Mattace-Raso FUS, van der Cammen TJM, Hofman A, et al. Arterial stiffness and risk of coronary heart disease and stroke: the Rotterdam Study. Circulation. 2006; 113(5): 657-663, doi: 10.1161/CIRCULATIONAHA.105.555235, indexed in Pubmed: 16461838 .

9. van Sloten TT, Schram MT, van den Hurk K, et al. Local stiffness of the carotid and femoral artery is associated with incident cardiovascular events and all-cause mortality: the Hoorn study. J Am Coll Cardiol. 2014; 63(17): 1739-1747, doi: 10.1016/j. jacc.2013.12.041, indexed in Pubmed: 24583306.

10. Williams B, Mancia G, Spiering W, et al. 2018 ESC/ESH Guidelines for the management of arterial hypertension. Eur Heart J. 2018; 39(33): 3021-3104, doi: 10.1093/eurheartj/ehy339, indexed in Pubmed: 30165516.

11. Cruickshank K, Riste L, Anderson SG, et al. Aortic pulse-wave velocity and its relationship to mortality in diabetes and glucose intolerance: an integrated index of vascular function? Circulation. 2002; 106(16): 2085-2090, indexed in Pubmed: 12379578.

12. Vlachopoulos C, Aznaouridis K, Stefanadis C. Aortic stiffness for cardiovascular risk prediction: just measure it, just do it! J Am Coll Cardiol. 2014; 63(7): 647-649, doi: 10.1016/j. jacc.2013.10.040, indexed in Pubmed: 24239659.

13. Greve S, Laurent S, Olsen M. Estimated pulse wave velocity calculated from age and mean arterial blood pressure. Pulse. 2016; 4(4): 175-179, doi: 10.1159/000453073.
14. Mancia G, Fagard R, Narkiewicz K, et al. 2013 ESH/ESC guidelines for the management of arterial hypertension: the Task Force for the Management of Arterial Hypertension of the European Society of Hypertension (ESH) and of the European Society of Cardiology (ESC). Blood Pressure. 2013; 22(4): 193-278, doi: 10.3109/08037051.2013.812549.

15. Peasey A, Bobak M, Kubinova R, et al. Determinants of cardiovascular disease and other non-communicable diseases in Central and Eastern Europe: rationale and design of the HAPIEE study. BMC Public Health. 2006; 6: 255, doi: 10.1186/1471-2458-6-255, indexed in Pubmed: 17049075.

16. Conroy RM, Pyörälä K, Fitzgerald AP, et al. Estimation of ten-year risk of fatal cardiovascular disease in Europe: the SCORE project. Eur Heart J. 2003; 24(11): 987-1003, indexed in Pubmed: 12788299

17. Asmar R, Benetos A, Topouchian J, et al. Assessment of Arterial Distensibility by Automatic Pulse Wave Velocity Measurement. Hypertension. 1995; 26(3): 485-490, doi: 10.1161/01.hyp.26.3.485.

18. Van Bortel LM, Laurent S, Boutouyrie P, et al. Expert consensus document on the measurement of aortic stiffness in daily practice using carotid-femoral pulse wave velocity. J Hypertens. 2012; 30(3): 445-448, doi: 10.1097/HJH.0b013e32834fa8b0, indexed in Pubmed: 22278144.

19. Perk J, Backer GDe, Gohlke H, et al. European Guidelines on Cardiovascular Disease Prevention in Clinical Practice (Version 2012). Int J Behav Med. 2012; 19(4): 403-488, doi: 10.1007/s12529-012-9242-5.

20. Hobbs FDR, Piepoli M, Hoes A, et al. 2016 European Guidelines on cardiovascular disease prevention in clinical practice. Eur Heart J. 2016; 37(29): 2315-2381, doi: 10.1093/eurheartj/ehw106.

21. Graham I, Atar D, Borch-Johnsen K, et al. European Society of Cardiology (ESC) Committee for Practice Guidelines (CPG). European guidelines on cardiovascular disease prevention in clinical practice: executive summary: Fourth Joint Task Force of the European Society of Cardiology and Other Societies on Cardiovascular Disease Prevention in Clinical Practice. Eur Heart J. 2007; 28(19): 2375-2414, doi: 10.1093/eurhearti/ehm316, indexed in Pubmed: 17726041.

22. Wohlfahrt P, Krajčoviechová A, Seidlerová J, et al. Arterial stiffness parameters: how do they differ? Atherosclerosis. 2013; 231(2): 359-364, doi: 10.1016/j.atherosclerosis.2013.10.006, indexed in Pubmed: 24267252.

23. Chen BW, Wang ZG, Liu Q, et al. Combination of pulse wave velocity with clinical factors as a promising tool to predict major adverse cardiac events after percutaneous coronary intervention. J Cardiol. 2015; 65(4): 318-323, doi: 10.1016/j.jjcc.2014.06.010, indexed in Pubmed: 25048178.

24. Choo J, Shin C, Barinas-Mitchell E, et al. Regional pulse wave velocities and their cardiovascular risk factors among healthy middle-aged men: a cross-sectional population-based study. BMC Cardiovasc Disord. 2014; 14: 5, doi: 10.1186/1471-2261-14-5, indexed in Pubmed: 24410766.

25. Broda G, Rywik S. Wieloośrodkowe ogólnopolskie badanie stanu zdrowia ludności - projekt WOBASZ. Zdefiniowanie problemu oraz cele badania. Kardiol Pol. 2005: 63.

26. Zdrojewski Ł, Zdrojewski T, Rutkowski M, et al. Prevalence and control of cardiovascular risk factors in Poland. Assumptions and objectives of the NATPOL 2011 Survey. Kardiol Pol. 2013; 71(4): 381-392, doi: 10.5603/KP.2013.0066, indexed in Pubmed: 23788344

27. Pędziński B, Kurianiuk A, Pędziński W, et al. Ocena zagrożenia chorobami układu krążenia w oparciu o realizację programu profilaktyki w podstawowej opiece zdrowotnej. Probl Hig Epidemiol. 2011; 92: 397-404.

28. Piwońska A, Piotrowski W, Piwoński J, et al. Cardiovascular health knowledge of the Polish population. Comparison of two national multi-centre health surveys: WOBASZ and WOBASZ II. Kardiol Pol. 2017; 75(7): 711-719, doi: 10.5603/KP.a2017.0070, indexed in Pubmed: 28394004. 
29. Piotrowski W, Waśkiewicz A, Cicha-Mikołajczyk A. Global cardiovascular mortality risk in the adult Polish population: prospective assessment of the cohorts studied in multicentre national WOBASZ and WOBASZ Senior studies. Kardiol Pol. 2016; 74(3): 262-273, doi: 10.5603/KP.a2015.0175, indexed in Pubmed: 26365939.

30. Greve SV, Blicher MK, Blyme A, et al. Association between albuminuria, atherosclerotic plaques, elevated pulse wave velocity, age, risk category and prognosis in apparently healthy individuals. J Hypertens. 2014; 32(5): 1034-1041, doi: 10.1097/HJH.0000000000000147, indexed in Pubmed: 24621803.

31. Kidawa M, Krzeminska-Pakula M, Peruga JZ, et al. Arterial dysfunction in syndrome X: results of arterial reactivity and pulse wave propagation tests. Heart. 2003; 89(4): 422-426, indexed in Pubmed: 12639871.

32. Kopeć G, Podolec P, Podolec J, et al. Atherosclerosis progression affects the relationship between endothelial function and aortic stiffness. Atherosclerosis. 2009; 204(1): 250-254, doi: 10.1016/j. atherosclerosis.2008.09.003, indexed in Pubmed: 18922528.

33. Mizia-Stec K, Haberka M, Mizia M, et al. Coronary artery calcium score assessed by a 64 multislice computed tomography and early indexes of functional and structural vascular remodeling in cardiac syndrome X patients. J Nucl Cardiol. 2008; 15(5): 655-662, doi: 10.1016/j.nuclcard.2008.06.006, indexed in Pubmed: 18761268.

34. Schneider A, Gawęcka J, Minczykowski A, et al. Arterial structure and function in patients with acute coronary syndrome after 1year treatment. Pol Arch Intern Med. 2017; 127(3): 184-189, doi: 10.20452/pamw.3939, indexed in Pubmed: 28220768.

35. Krasińska B, Miazga A, Cofta S, et al. Effect of eplerenone on the severity of obstructive sleep apnea and arterial stiffness in patients with resistant arterial hypertension. Pol Arch Med Wewn. 2016; 126(5): 330-339, doi: 10.20452/pamw.3410, indexed in Pubmed: 27230560

36. Topor-Madry R, Bobak M, Pajak A. 5-Year mortality in respondents and non-respondent for the cohort study of 20, 000 randomly selected middle aged men and women. The HAPIEE Project. Eur J Prev Cardiol. 2012; 19: S71.

37. Vikhireva O, Pajak A, Broda G, et al. SCORE performance in Central and Eastern Europe and former Soviet Union: MONICA and HAPIEE results. Eur Heart J. 2014; 35(9): 571-577, doi: 10.1093/eurheartj/eht189, indexed in Pubmed: 23786858.

Cite this article as: Podolec M, Siniarski A, Pająk A, et al. Association between carotid-femoral pulse wave velocity and overall cardiovascular risk score assessed by the SCORE system in urban Polish population. Kardiol Pol. 2019; 77(3): 363-370, doi: 10.5603/KP.a2019.0028.

\section{WHAT IS NEW?}

The Systemic COronary Risk Estimation (SCORE) system is well established for the assessment of cardiovascular disease (CVD) risk. To the best of our knowledge, this is the first study to evaluate carotid-femoral pulse wave velocity (CFPWV) in relation to the SCORE CVD risk assessment in a Polish population. Additionally, our study is the first to describe the distribution of CFPWV in the adult, urban Polish population and to examine the association between CFPWV and CVD risk assessed by the SCORE system. The calculated CFPWV cut-off point to differentiate between patients with low and high CVD risk was $11.7 \mathrm{~m} / \mathrm{s}$ (with $58.6 \%$ sensitivity and $71.3 \%$ specificity). 